\title{
Adding carbimazole to levothyroxine increases triiodothyronine and improves outcome in patients with primary hypothyroidism: a preliminary study from Egypt
}

Khaled Nagy Elfayoumy ${ }^{1}$, Usama Bahgat Elgazzar ${ }^{2}$, Mohamed Aboalabbas $^{3}$, Ahmed Salama Al-Adl ${ }^{1}$

${ }^{1}$ Internal Medicine Department, Faculty of Medicine, Al-Azhar University, New Damietta, Damietta, Egypt

${ }^{2}$ Biochemistry Department, Faculty of Medicine, Al-Azhar University, New Damietta, Damietta, Egypt

${ }^{3}$ Psychiatry Department, Faculty of Medicine, Al-Azhar University, New Damietta, Damietta, Egypt

Type of article: Original

\begin{abstract}
Background: Many hypothyroid patients are not tolerant and not satisfied with levothyroxine (LT4). Older studies used large doses of both carbimazole and LT4 for Hashimoto's thyroiditis (HT), because Graves' disease (GD) and HT were considered as very closely related syndromes produced by thyroid autoimmunity.

Objective: The aim of the study was to determine the outcome after adding small doses of carbimazole to reduced doses of LT4 for patients with primary hypothyroidism, who are unable to tolerate LT4.

Methods: The study is a non-randomized, single arm, interventional study. It included 19 female patients diagnosed with primary hypothyroidism who could not tolerate LT4. Subjects were recruited from the outpatient clinic of AL-Azhar University Hospital in Damietta, Egypt from January to March 2015. They were divided into two groups; group 1 included 10 patients with HT and 2 patients with non-specified primary hypothyroidism, and group 2 included 7 patients with subtotal thyroidectomy for GD. All patients received carbimazole (10 $\mathrm{mg} /$ day) beside LT4 ( $25 \mu \mathrm{g}$ thrice/week) for 10 weeks. Statistical analysis of the data was done by SPSS version 20, using paired-sample t-test, ANOVA, Chi square, and Pearson coefficient test.

Results: There was significant increase in free triiodothyronine (FT3) in addition to significant improvement in depression and LT4 tolerance in the whole population. There was non-significant improvement in TSH in group 1 $(\mathrm{p}=0.053)$. Surprisingly, in group 2 , in spite of significant increase in TSH $(\mathrm{p}=0.007)$ and non-significant decrease in free thyroxine (FT4), there was non-significant increase in FT3. Whether carbimazole improves the pathology of the hypothyroid gland or the peripheral deiodination of T4 to T3 (where the serum and tissue levels of the latter may be responsible for improvement of symptoms) is in need of investigation.

Conclusions: Adding carbimazole to LT4 improves FT3, LT4 tolerance, and depression in primary hypothyroid female patients. Further studies are required to determine the appropriate doses of this regimen in different cases.

Clinical trial registration: This study was registered at Thai Clinical Trials Registration center (http://www.clinicaltrials.in.th) with registration ID: TCTR20170123003.

Funding: The study received no fund or grant.

Keywords: Primary hypothyroidism, Carbimazole, Levothyroxine, Triiodothyronine
\end{abstract}

\section{Introduction}

Levothyroxine (LT4) is still the standard therapy for hypothyroidism. It is widely accepted, however, subjects under LT4 therapy have poorer quality of life (QOL) and more symptoms of depression than subjects with no thyroid disease even if biochemically euthyroid. Meanwhile, there are many unresolved issues regarding achieving clinical and biochemical euthyroidism and patient satisfaction (1-3). In addition, many patients cannot tolerate LT4, and suffer from symptoms such as palpitations, anxiety, and headaches, even when their thyroid hormone levels are still low and serum TSH levels are elevated. In that case, the American Thyroid Association (ATA) guidelines

\section{Corresponding author:}

Khaled Nagy Elfayoumy, Internal Medicine Department, Faculty of Medicine, Al-Azhar University, New Damietta, Damietta, Egypt.

Tel.:+201003778745, Fax:+20572404035. Email: kh_elfayoumy@yahoo.com,kh_elfayoumy@azhar.edu.eg Received: October 08, 2016, Accepted: January 24, 2017, Published: February $201 \overline{7}$

iThenticate screening: January 15, 2017, English editing: February 02, 2017, Quality control: February 10, 2017

(C) 2017 The Authors. This is an open access article under the terms of the Creative Commons Attribution-NonCommercialNoDerivs License, which permits use and distribution in any medium, provided the original work is properly cited, the use is non-commercial and no modifications or adaptations are made. 
recommend reducing the LT4 dose then up-titrating it slowly (1). Alternatively, both LT4 and carbimazole may be used together as a block-replace regimen in Graves' disease (GD), to get further benefit from the immunomodulating action of carbimazole (4). The relationship between Hashimoto's thyroiditis (HT) and GD, however, is so interlaced that pathogenesis and pathology may overlap. Moreover, it is believed that both may co-exist in the same patient (5, 6). So, it was suggested that carbimazole may have an important role in treatment of human autoimmune (AI) thyroid diseases of either GD or HT. Also, it was found that methimazole (the active metabolite of carbimazole, not available in our country) significantly reduced the severity of experimental AI thyroid disease in rats $(7,8)$. We hypothesized that carbimazole may improve outcome for patients with primary hypothyroidism (or at least some categories) when added to LT4. The aim of this study was to determine thyroid hormone levels, LT4 tolerance and depression symptoms after adding small doses of carbimazole to reduced doses of LT4 for primary hypothyroid patients (with either AI hypothyroidism or subtotal thyroidectomy for GD) who were intolerant to LT4 therapy.

\section{Material and Methods \\ 2.1. Participants}

The study is a non-randomized, single arm, interventional, preliminary study. Subjects were hypothyroid attendants of the outpatient clinic of AL-Azhar University Hospital in Damietta, Egypt from January to March, 2015. Eligible participants were adult female patients, aged 18 years or over, who had previously been diagnosed with primary hypothyroidism (by a qualified medical practitioner or specialist), and were on stable doses of LT4 for at least 6 months, but were unable to tolerate it without reaching a thyrotoxic state. For LT4 intolerance, we used a studyspecific questionnaire. The questions included the four principal adverse reactions from LT4 therapy making the patient non-tolerant (palpitations, anxiety, headaches, and insomnia) (1,9-11). The 4-items require a response on whether each of the given symptoms had been significantly experienced during the last 3 months. Symptoms were worth zero when absent, one point when mild, 2 when moderate, or 3 points when severe. Thus, the maximum score is 12 points. We considered subjects having scores $\geq 6$ as intolerant to LT4, hence were eligible for the study. Exclusion criteria included patients with: congenital hypothyroidism, any thyroidectomy (except subtotal for GD), thyroid diseases treated with radioiodine, coronary heart disease, anemia, uncontrolled hypertension or diabetes mellitus, or significant liver, renal or respiratory disease. Subjects using antidepressants or other drugs that may influence thyroid function or alter T4 metabolism were also excluded. Pregnant or lactating women or those planning for pregnancy during the study period were excluded too.

\subsection{Design and Intervention}

The study included 19 hypothyroid patients (aged 23-67 years) who met the inclusion and exclusion criteria. They were divided into two groups. Group 1 included 12 patients; 10 patients with HT that was diagnosed by clinical examination and positive thyroid peroxidase antibodies (TPO Ab). One patient had negative TPO Ab, but had typical fine needle cytology of HT. The other 2 patients were classified as non-specified (idiopathic) primary hypothyroidism. Those 2 patients had negative TPO Ab but unfortunately, they didn't have fine needle cytology. They might, however, have HT with negative TPO Ab after long duration of LT4 therapy $(5,12)$. Group 2 included 7 patients with subtotal thyroidectomy for GD in whom diagnoses were confirmed by surgical pathology reports. All patients received carbimazole $10 \mathrm{mg} /$ day in addition to $25 \mu \mathrm{g}$ of LT4, 1-hour before breakfast three days/week (on Saturday, Monday, and Wednesday), for 10 weeks. We reduced LT4 dose as per ATA guidelines (1). Also, our nonpublished experience is that patients are unable to tolerate large doses of LT4 with carbimazole. The rationale behind the low carbimazole dose in the present study is that previous studies used large doses (30-45 mg/day) in front of large LT4 dose (150 $\mu \mathrm{g} /$ day), but LT4 is already reduced for non-tolerant patients in our study $(7,13,14)$. We were cautious not to increase the number of enrolled participants, as there are no experimental data to support such intervention. At the start and end of the study, we evaluated LT4 tolerance and depression symptoms for the patients. Also, at the start of the study and on Tuesdays at the end of the study, fasting blood samples were drawn for free thyroxine (FT4), free triiodothyronine (FT3), TSH, and TPO Ab. In addition, at the start of the study, we measured the lipid profile, and complete blood count and 12-lead ECG were done to exclude causes simulating LT4 intolerance.

\subsection{Psychiatric Evaluation}

Depression was assessed using Montgomery-Asberg Depression Rating Scale (MADRS) which is sensitive to changes brought on by treatment. Also, it is useful in measuring the degree of severity of depression, especially in patients with organic diseases. It consists of 10 items: Each item yields a score of 0 to 6 . The following are the cutoff points: 0-6 (no depression), 7-19 (mild depression), 20-33 (moderate depression), 34-44 (severe depression), $>44$ (very severe depression) (15). 


\subsection{Specimen Collection}

Five $\mathrm{mL}$ of blood were aspirated from each patient, left in incubator for $30 \mathrm{~min}$ at $37{ }^{\circ} \mathrm{C}$, and then serum was separated and kept frozen in aliquots at $-80^{\circ} \mathrm{C}$ until analyzed. Lipid profile is performed by the automated BT 3500 instrument. It is an automatic analyzer random access for clinical-chemistry and immunoturbidimetry (Biotecnica Instruments, Via Licenza, 18- 00156, Rome-Italy). FT3, FT4, TSH and TPO Ab assays were performed by a solidphase, competitive chemiluminescent enzyme immunoassay on IMMULITE system (Siemens Medical Solutions Diagnostics Technical Services Department, USA). Reference ranges for TSH, FT3, and FT4 were (0.4-4.0 mIU/L), (2.3-6.3 pmol/L), and (10.3-24.5 pmol/L) respectively. Levels of TPO Ab $>35 \mathrm{UI} / \mathrm{mL}$ were considered positive.

\subsection{Statistical Analysis}

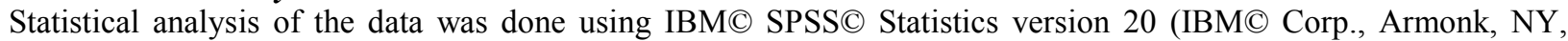
USA). Continuous data were presented in the form of mean and standard deviation (SD), and categorical data as number and percent. Continuous data were tested for normality of distribution prior to any statistical analysis. The Paired-samples t-test was used to compare between means before and after intervention for continuous data. ANOVA test was used for comparison of continuous data among three groups or more. For comparison between categorical data, chi- square test was used. Correlations were performed using the Pearson coefficient test. Statistical significant difference was considered at $\mathrm{p}<0.05$.

\subsection{Ethical Approval}

The study was registered and approved by the local institutional ethical committee, and all procedures were in accordance with the standards of the 1964 Helsinki Declaration and its later amendments ethical standards. Informed consent was obtained from each participant included in the study.

\section{Results}

\subsection{Base line characteristics (Tables 1,2)}

The mean age of our subjects was $43.3 \pm 14.7$ years, and the mean previous LT4 duration (the positive study control) was $45.2 \pm 38.1$ months. They had normal lipid profile (one patient had mild elevation in total cholesterol; 216 $\mathrm{mg} / \mathrm{dL}$ ). Nearly all patients (exactly 18 patients) were complaining of palpitation, indeed one patient in group 2 had recurrent attacks of paroxysmal atrial fibrillation (AF) with history of ICU admissions after being replaced with LT4. She had grade 2 depression. Interestingly, AF attacks disappeared throughout the study period. Three patients in each group were euthyroid (considered by TSH within the reference range). Only one subject had no depression while the other 18 subjects had some degrees of depression, but there were no cases of very severe depression.

Table 1. General characteristics of the patients at the base line of the study

\begin{tabular}{|l|l|}
\hline Variable & Statistics; $\mathrm{n}(\%) /$ Mean \pm SD \\
\hline Age (year) & $43.3 \pm 14.7$ \\
\hline Hashimoto thyroiditis & $10(53 \%)$ \\
\hline Idiopathic hypothyroidism & $2(10 \%)$ \\
\hline Post-surgical & $7(37 \%)$ \\
\hline Previous LT4 dose (ug/day) & $81.6 \pm 32.1$ \\
\hline Previous LT4 duration (in months) & $45.2 \pm 38.1$ \\
\hline Positive TPO Ab & $12(63.2 \%)$ \\
\hline SBP & $117.4 \pm 14.8$ \\
\hline DBP & $74.7 \pm 10.7$ \\
\hline Pulse rate/minute & $84.6 \pm 6.3$ \\
\hline Total cholesterol $(<5.2 \mathrm{mmol} / \mathrm{L})$ & $3.79 \pm 0.897$ \\
\hline LDL $(<3.36 \mathrm{mmol} / \mathrm{L})$ & $2.1 \pm 0.685$ \\
\hline HDL $(>1.29 \mathrm{mmol} / \mathrm{L})$ & $1.269 \pm 0.284$ \\
\hline TG $(<1.69 \mathrm{mmol} / \mathrm{L})$ & $0.878 \pm 0.5$ \\
\hline Hb $(\mathrm{g} / \mathrm{dl})$ & $12.4 \pm 0.8$ \\
\hline WBCs & $6.3 \pm 2.3$ \\
\hline Platelets & $206 \pm 89$ \\
\hline SBP: systo
\end{tabular}

SBP: systolic blood pressure; DBP: diastolic blood pressure; LDL: low-density lipoprotein; HDL: high-density lipoprotein; VLDL: very low-density lipoprotein; TG: triglycerides; Hb: haemoglobin; WBCs: white blood cells 
Table 2. General characteristics of the patients in each group at the base line

\begin{tabular}{|l|l|l|}
\hline \multirow{2}{*}{ Variable } & \multicolumn{2}{|l|}{ Statistics; $\mathrm{n}(\%) /$ Mean \pm SD } \\
\cline { 2 - 3 } & Group 1 & Group 2 \\
\hline Age (year) & $42.9 \pm 15.1$ & $43.9 \pm 15.1$ \\
\hline Previous LT4 dose (ug/day) & $77.1 \pm 31$ & $89.3 \pm 34.9$ \\
\hline Previous LT4 duration (in months) & $35 \pm 32.4$ & $62.6 \pm 43.2$ \\
\hline Positive TPO Ab & $9(69.2 \%)$ & $3(42.9 \%)$ \\
\hline SBP & $118.3 \pm 14.7$ & $115.7 \pm 16.2$ \\
\hline DBP & $75 \pm 11.7$ & $74.3 \pm 9.8$ \\
\hline Pulse rate/minute & $83 \pm 6.6$ & $87.4 \pm 5$ \\
\hline Total cholesterol $(<5.2 \mathrm{mmol} / \mathrm{L})$ & $3.77 \pm 1.08$ & $3.8 \pm 0.5$ \\
\hline LDL $(<3.36 \mathrm{mmol} / \mathrm{L})$ & $1.98 \pm 0.79$ & $2.23 \pm 0.42$ \\
\hline HDL $(>1.29 \mathrm{mmol} / \mathrm{L})$ & $1.298 \pm 0.336$ & $1.22 \pm 0.17$ \\
\hline TG $(<1.69 \mathrm{mmol} / \mathrm{L})$ & $1.043 \pm 0.55$ & $0.597 \pm 0.20$ \\
\hline Hb $(\mathrm{g} / \mathrm{dl})$ & $12.7 \pm 0.9$ & $11.9 \pm 0.4$ \\
\hline WBCs & $7 \pm 2.5$ & $5.2 \pm 1.4$ \\
\hline Platelets & $235.8 \pm 92.1$ & $155 \pm 58.3$ \\
\hline
\end{tabular}

SBP: systolic blood pressure; DBP: diastolic blood pressure; LDL: low-density lipoprotein; HDL: high-density lipoprotein; VLDL: very low-density lipoprotein; TG: triglycerides; Hb: haemoglobin; WBCs: white blood cells

\subsection{Outcome measures}

3.2.1. In the whole population (Table 3)

While there was significant increase in FT3 and FT3/FT4 ( $<<0.001$ and $p=0.004$ respectively), there was nonsignificant decrease in TSH with non-significant increase in FT4 ( $\mathrm{p}=0.934$ and 0.224 respectively). In addition, there was significant improvement in depression and symptoms of LT4 intolerance ( $p=0.017$ and $p<0.001$ respectively). There is a tendency towards positive correlation between serum FT3 and improved LT4 intolerance $(\mathrm{p}=0.095)$, and, to a lesser degree, between the former and grades of depression by ANOVA ( $\mathrm{p}=0.165)$. Positive TPO Ab did not convert negative at the end of the study.

\subsubsection{In Group 1 (Table 4)}

After having abnormally elevated TSH, 4 patients (33\% of group subjects) achieved normal TSH at the end of the study. Another 2 patients remained biochemically euthyroid. In general, there was a trend towards TSH improvement in this group as a whole $(\mathrm{p}=0.053)$.

FT3 and FT3/FT4 were significantly increased ( $<<0.001$ for both), while increase in FT4 was insignificant $(\mathrm{p}=0.963)$. There was significant improvement in symptoms of LT4 intolerance and depression $(\mathrm{p}<0.001$ and $\mathrm{p}=0.037$ respectively). Comparison between grades of depression showed significant correlation with increased FT3 $(\mathrm{p}=0.010)$.

\subsubsection{In Group 2 (Table 4)}

In spite of significant increase in TSH $(\mathrm{p}=0.007)$ and non-significant decrease in FT4 $(\mathrm{p}=0.187)$ (as we reduced LT4 dose), there was non-significant increase in FT3 and FT3/FT4 ( $\mathrm{p}=0.385$, and 0.079 respectively) with significant improvement in symptoms of LT4 intolerance $(\mathrm{p}<0.001)$, and non-significant improvement in depression $(\mathrm{p}=0.247)$. There was a tendency towards significant correlation between increased FT3 and both symptoms of LT4 intolerance and depression ( $\mathrm{p}=0.143,0.198$ respectively).

Table 3. The thyroid hormone levels of the whole population at the base line vs. at the end of the study

\begin{tabular}{|l|l|l|l|l|}
\hline \multirow{2}{*}{ Variable } & at the base line & at the end & \multicolumn{2}{|c|}{ Paired-samples t-test } \\
\cline { 2 - 5 } & Mean \pm SD & Mean \pm SD & t & p-value \\
\hline TSH & $7.7 \pm 7.4$ & $7.5 \pm 5.3$ & 0.084 & 0.934 \\
\hline FT3 & $3.1 \pm 0.768$ & $4.5 \pm 1.22$ & 4.726 & $<0.001$ \\
\hline FT4 & $14.2 \pm 3.86$ & $11.6 \pm 3.86$ & 1.260 & 0.224 \\
\hline FT3/FT4 ratio & $0.24 \pm 0.06$ & $0.45 \pm 0.30$ & 3.054 & 0.004 \\
\hline
\end{tabular}

Reference range for TSH (0.4-4.0 mIU/L), FT3 (2.3-6.3 pmol/L), FT4 (10.3-24.5 pmol/L) 
http://www.ephysician.ir

Table 4. Data of both groups; at the base line vs. at the end of the study

\begin{tabular}{|c|c|c|c|c|}
\hline \multicolumn{3}{|l|}{ Parameters } & Group 1 & Group 2 \\
\hline \multirow[t]{12}{*}{ Thyroid profile } & \multirow[t]{3}{*}{$\mathrm{TSH}$} & At the base line & $10 \pm 8.1$ & $3.8 \pm 3.8$ \\
\hline & & At the end & $4.9 \pm 3$ & $12 \pm 5.5$ \\
\hline & & p-value & 0.053 & 0.007 \\
\hline & \multirow[t]{3}{*}{ FT3 } & At the base line & $2.9 \pm 0.768$ & $3.4 \pm 0.768$ \\
\hline & & At the end & $4.8 \pm 1.22$ & $3.8 \pm 1.22$ \\
\hline & & p-value & $<0.001$ & 0.385 \\
\hline & \multirow[t]{3}{*}{ FT4 } & At the base line & $12.9 \pm 5.15$ & $15.4 \pm 3.86$ \\
\hline & & At the end & $13 \pm 2.57$ & $10.3 \pm 6.43$ \\
\hline & & p-value & 0.963 & 0.187 \\
\hline & \multirow[t]{3}{*}{ FT3/FT4 } & At the base line & $0.24 \pm 0.07$ & $0.23 \pm 0.05$ \\
\hline & & At the end & $0.38 \pm 0.08$ & $0.58 \pm 0.48$ \\
\hline & & p-value & $<0.001$ & 0.079 \\
\hline \multirow[t]{9}{*}{ Grades of depression } & \multirow[t]{2}{*}{ Grade 0 (no depression); $\mathrm{n}(\%)$} & At the base line & $0(0)$ & $1(14.3)$ \\
\hline & & At the end & $4(33.3)$ & $2(28.6)$ \\
\hline & \multirow[t]{2}{*}{ Grade 1 (mild depression); $\mathrm{n}(\%)$} & At the base line & $2(16.7)$ & $2(28.6)$ \\
\hline & & At the end & $4(33.3)$ & $4(57.1)$ \\
\hline & \multirow[t]{2}{*}{ Grade 2 (moderate depression); $\mathrm{n}(\%)$} & At the base line & $7(58.3)$ & $4(57.1)$ \\
\hline & & At the end & $4(33.3)$ & $1(14.3)$ \\
\hline & \multirow[t]{2}{*}{ Grade 3 (severe depression); n (\%) } & At the base line & $3(25)$ & 0 \\
\hline & & At the end & $0(0)$ & 0 \\
\hline & \multicolumn{2}{|l|}{ p-value } & 0.037 & 0.247 \\
\hline \multirow[t]{3}{*}{ Score of LT4 intolerance } & \multicolumn{2}{|l|}{ At the base line } & $7.3 \pm 2$ & $8.1 \pm 0.9$ \\
\hline & \multicolumn{2}{|l|}{ At the end } & $2.1 \pm 1.9$ & $3.1 \pm 2.1$ \\
\hline & \multicolumn{2}{|l|}{$\mathrm{p}$-value } & $<0.001$ & $<0.001$ \\
\hline
\end{tabular}

Reference range for TSH (0.4-4.0 mIU/L), FT3 (2.3-6.3 pmol/L), FT4 (10.3-24.5 pmol/L), Maximum score of LT4 intolerance; 12 = worst symptoms

\section{Discussion}

Thyroid hormones regulate the function and metabolism of nearly all organs of the body, and their action is affected by plasma transport, deiodination, and transmembrane transport (16). It has been suggested that hypothyroid patients, even when adequately replaced with LT4, have increased morbidity and mortality (17). So, there is an unanswered question: where patients' dissatisfaction results from? First of all, we remember that the therapeutic benefit of LT4 replacement depends on its peripheral conversion into T3 (18) and the intracellular concentration of the latter is dependent on its transport from the circulation as well as intracellular deiodination of the former. However, LT4 replacement didn't seem to result in adequate T3 concentrations in all tissues in both animal and human studies (19-22). Therefore, athyreotic patients often need TSH-suppressive doses of LT4 to reach the normal preoperative levels of FT3 (23). The present study revealed improvement in depression and symptoms of LT4 intolerance in the hypothyroid populations. The better results being in group 1 rather than group 2 , may be due to insufficient LT4 doses for those who underwent surgery. The increased serum FT3 (although insignificant in group 2) may be responsible for improvement in outcome. However, the absence of frank correlation between increased serum FT3 and symptoms in most cases may be due to the small sized sample. Another explanation is that the unmeasured tissue (e.g. the brain) level may be the responsible one for improvement of symptoms (24). In agreement with that, patients treated with combined levothyroxine and liothyronine (LT4 and LT3) therapy showed no improvement in wellbeing despite higher plasma levels of T3 compared with those treated with traditional T4 therapy $(25,26)$. Again, about $60 \%$ of circulating T3 is estimated to originate from the deiodinase 2 (D2) pathway in normal subjects (27). So, why do LT4-treated hypothyroid patients have insufficient T3 production? Bianco AC et al. suggested inhibitory effect of LT4 replacement on D2. The other explanation is that different tissues express D2 and transporters in different quantity and quality, and have different abilities to compensate for low T3 levels (19, 28). On the same line, van der Deure WM et al. found a polymorphism in the gene for thyroid hormone transporter OATP1C1 to be associated with fatigue and depression in subjects on LT4. Whereas Panicker V et al. found that polymorphism in D2 is associated with poorer psychological well-being in subjects on combined LT4 and LT3 (24, 29). This study revealed significant increase in FT3/FT4 ratio which is an indicator of increased peripheral deiodination (30). So, the increase in FT3 is mostly due to peripheral D2 activation rather than other causes such as 
changes in plasma proteins. Now, the current question is; could carbimazole enhance D2 activity (widely distributed in various tissues) or express more transporters? So far, the answer is still pending, but it seems likely, especially as propylthyouracil (the other antithyroid drug) impacts deiodination although with a reverse action (27). In summary, patients treated with LT4 are non-tolerant and non-satisfied with such therapy due to "imbalance" between increased serum levels of T4 (or at least peaked levels) with lower LT3 levels (23). So, normalization of serum TSH levels in these cases does not reflect peripheral tissue euthyroidism; it only reflects the feedback effect of thyroid hormones at the hypothalamic-pituitary level (31). Some authors suggested that autoimmune markers, independent of thyroid function, indicate poor QOL and depression (32). However, positive TPO Ab (a marker of thyroid autoimmunity) did not convert at the end of our study, predominantly because we used low doses of both LT4 and carbimazole. Previous studies documented decrease in TPO Ab titers after large doses of LT4 (with or without carbimazole) for longer duration, even in euthyroid patients $(7,33)$. The non-changed positive TPO Ab in our study indicates absence of relation between improvement of symptoms and AI markers per se. This is logic reasoning owing to; firstly; many patients (including some patients in this study) were TPO Ab negative but still complaining even if they were euthyroid. Secondly; standard LT4 therapy (with which the patients may not be satisfied) has been found to decrease TPO Ab titer (7, 12, and 14). Thirdly; our study population experienced dramatic clinical improvement by this regimen within days. In agreement with this hypothesis, a study of Engum et al. did not find any association between presence of TPO Ab and depression or anxiety in 745 euthyroid subjects (34). Another striking finding in our study is that FT4 didn't decrease in group 1 (mainly with HT). Instead, there was non-significant increase in FT4, with tendency towards significant improvement in TSH, despite decrease in prescribed LT4 doses. Jansson et al. suggested that immunosuppressive effects might be achieved not only by classic drugs acting on the immunocompetent cells, but also by drugs altering the target cells within the immune-injured organ causing reduction in AI stimuli (14). So, the other question is: Could "carbimazole" play this role in our case? Did it improve the pathology of the hypothyroid gland so that it regained some function and resumed hormonal synthesis and secretion? Surely it has an immunomodulating effect in GD (35), but it became clear that HT and GD are different expressions of a similar AI process (5). Moreover, these two clinically distinct diseases share common immunopathogenic mechanisms, and may also chair the same genes (36). Even conversion from one to the other has been reported $(37,38)$. So, the possible role of carbimazole in ameliorating the pathology of the hypothyroid gland remains a matter of investigation. The limitations of our study include small non-randomized sample. The study didn't include cases with severe hypothyroidism. Also, D2 activity was not measured in our study. The strengths of our study are adequate duration of therapy, evaluation of both subjective and biochemical measures, and a homogeneous group of subjects.

\section{Conclusions}

Adding carbimazole to LT4, increases serum FT3, and improves LT4 tolerance and depression in primary hypothyroid female patients. Larger randomized studies are required to confirm these data, and to determine the appropriate doses of this regimen in different cases. The pathophysiology of hypothyroidism is not restricted to the affected gland, but it extends to the target tissues of its hormones. Hence, just normalization of serum TSH is not sufficient to expect patients' satisfaction.

\section{Acknowledgments:}

We gratefully thank Professor Mohammad K Senna, Professor of Rheumatology, for his skillful assistance in statistical analysis. We also thank the efforts of Doctor Mesbah Elmansy, Demonstrator of Internal Medicine. Finally, we appreciate the help and support of Professor. Tarek Emran Professor of Clinical Pathology. This work was presented in the $15^{\text {th }}$ International Thyroid Congress in Florida, USA (ID: 549)

\section{Conflict of Interest:}

There is no conflict of interest to be declared.

\section{Authors' contributions:}

All authors contributed to this project and article equally. All authors read and approved the final manuscript.

\section{Clinical trial registration:}

This study was registered at Thai Clinical Trials Registration center (http://www.clinicaltrials.in.th) with registration ID: TCTR20170123003.

\section{Funding:}

The study received no fund or grant. 


\section{References:}

1) Jonklaas J, Bianco AC, Bauer AJ, Burman KD, Cappola AR, Celi FS, et al. Guidelines for the treatment of hypothyroidism: prepared by the American thyroid association task force on thyroid hormone replacement. Thyroid. 2014; 24(12): 1670-751. doi: 10.1089/thy.2014.0028. PMID: 25266247, PMCID: PMC4267409.

2) Dayan CM, Panicker V. Hypothyroidism and Depression. Eur Thyroid J. 2013; 2: 168-79. doi: 10.1159/000353777. PMID: 24847450, PMCID: PMC4017747.

3) Bianchi GP, Zaccheroni V, Solaroli E, Vescini F, Cerutti R, Zoli M, et al. Health-related quality of life in patients with thyroid disorders. Qual Life Res. 2004; 13: 45-54. doi: 10.1023/B:QURE.0000015315.35184.66. PMID: 15058786.

4) Abraham P, Acharya S. Current and emerging treatment options for Graves' hyperthyroidism. Ther Clin Risk Manag. 2010; 6: 29-40. PMID: 20169034, PMCID: PMC2817786.

5) Akamizu T, Amino N, DeGroot LJ: Hashimoto's Thyroiditis. In: De Groot LJ, Beck-Peccoz P, Chrousos G, Dungan K, Grossman A, Hershman JM, Koch C, McLachlan R, New M, Rebar R, Singer F, Vinik A, Weickert MO, editors. Endotext [Internet]. South Dartmouth (MA): MDText.com, Inc.; 2000-2013 Dec 20.

6) Dasari S, Naha K, Hande M, Vivek G. Hot and cold: coexistent Graves' disease and Hashimoto's thyroiditis in a patient with Schmidt's syndrome. BMJ Case Rep. 2014; 2014. doi: 10.1136/bcr-2013-010432. PMID: 24850545, PMCID: PMC4039812.

7) McGregor AM, Ibbertson HK, Smith BR, Hall R. Carbimazole and autoantibodv synthesis in Hashimoto's thyroiditis. BMJ. 1980; 281(6246): 968-9. doi: 10.1136/bmj.281.6246.968. PMID: 6893563, PMCID: PMC1714378.

8) Rennie DP, McGregor AM, Keast D, Weetman AP, Foord SM, Dieguez C, et al. The influence of methimazole on thyroglobulin-induced autoimmune thyroiditis in the rat. Endocrinology. 1983; 112(1): 326-30. doi: 10.1210/endo-112-1-326. PMID: 6847827.

9) Fernandez ME, Lopez SM, Cazaux A, Cambursano VH, Cortes JR. Insomnia: prevalence in Cordopa city hospital. Rev Fac Cien Med Univ Nac Cordoba. 2012; 69(4): 191-6. PMID: 23751785.

10) Valizadeh M, Seyyed-Majidi MR, Hajibeigloo H, Momtazi S, Musavinasab N, Hayatbakhsh MR. Efficacy of combined levothyroxine and liothyronine as compared with levothyroxine monotherapy in primary hypothyroidism: a randomized controlled trial. Endocr Res. 2009; 34: 80-9. doi: 10.1080/07435800903156340. PMID: 19701833.

11) Brown LK, Dedrick DL, Doggett JW, Guido PS. Antidepressant medication use and restless legs syndrome in patients presenting with insomnia. Sleep Med. 2005; 6(5): 443-50. doi: 10.1016/j.sleep.2005.03.005. PMID: 16084763.

12) Takasu N, Yamada T, Takasu M, Komiya I, Nagasawa Y, Asawa T. Disappearance of thyrotropin-blocking antibodies and spontaneous recovery from hypothyroidism in autoimmune thyroiditis. N Engl J Med. 1992; 326(8): 513-8. doi: 10.1056/NEJM199202203260803. PMID: 1732791.

13) Jansson R, Karlsson A, Forsum U. Intrathyroidal HLA-DR expression and T lymphocyte phenotypes in Graves' thyrotoxicosis, Hashimoto's thyroiditis and nodular colloid goitre. Clin Exp Immunol. 1984; 58(2): 264-72. PMID: 6238731, PMCID: PMC1577052.

14) Jansson R, Karlsson A, Dahlberg PA. Thyroxine, methimazole, and thyroid microsomal autoantibody titres in hypothyroid Hashimoto's thyroiditis. BMJ (Clin Res Ed). 1985; 290(6461): 11-2. doi: 10.1136/bmj.290.6461.11. PMID: 3917315, PMCID: PMC1415424.

15) Montgomery SA, Asberg M. A new depression scale designed to be sensitive to change. Br J Psychiatry. 1979; 134: 382-9. doi: 10.1192/bjp.134.4.382. PMID: 444788.

16) Brent GA. Mechanisms of thyroid hormone action. J Clin Invest. 2012; 122: 3035-43. doi: 10.1172/JCI60047. PMID: 22945636, PMCID: PMC3433956.

17) Thvilum M, Brandt F, Brix TH, Hegedus L. A review of the evidence for and against increased mortality in hypothyroidism. Nat Rev Endocrinol. 2012; 8(7): 417-24. doi: 10.1038/nrendo.2012.29. PMID: 22392154.

18) Braverman LE, Ingbar SH, Sterling K. Conversion of thyroxine (T4) to triiodothyronine (T3) in athyreotic human subjects. J Clin Invest. 1970; 49(5): 855-64. doi: 10.1172/JCI106304. PMID: 4986007, PMCID: PMC535757.

19) Escobar-Morreale HF, Obregón MJ, Escobar del Rey F, Morreale de Escobar G. Replacement therapy for hypothyroidism with thyroxine alone does not ensure euthyroidism in all tissues, as studied in thyroidectomized rats. J Clin Invest. 1995; 96(6): 2828-38. doi: 10.1172/JCI118353. PMID: 8675653, PMCID: PMC185993.

20) Iverson JF, Mariash CN. Optimal free thyroxine levels for thyroid hormone replacement in hypothyroidism. Endocr Pract. 2008; 14(5): 550-5. doi: 10.4158/EP.14.5.550. PMID: 18753096. 
21) Jonklaas J, Davidson B, Bhagat S, Soldin SJ. Triiodothyronine levels in athyreotic individuals during levothyroxine therapy. JAMA. 2008; 299(7): 769-77. doi: 10.1001/jama.299.7.769. PMID: 18285588.

22) Woeber KA. Levothyroxine therapy and serum free thyroxine and free triiodothyronine concentrations. J Endocrinol Invest. 2002; 25(2): 106-9. doi: 10.1007/BF03343972. PMID: 11929079.

23) Ito M, Miyauchi A, Morita S, Kudo T, Nishihara E, Kihara M, et al. TSH-suppressive doses of levothyroxine are required to achieve preoperative native serum triiodothyronine levels in patients who have undergone total thyroidectomy. Eur J Endocrinol. 2012; 167(3): 373-8. doi: 10.1530/EJE-11-1029. PMID: 22711760.

24) Panicker V, Saravanan P, Vaidya B, Evans J, Hattersley AT, Frayling TM, Dayan CM. Common variation in the DIO2 gene predicts baseline psychological well-being and response to combination thyroxine plus triiodothyronine therapy in hypothyroid patients. J Clin Endocrinol Metab. 2009; 94(5): 1623-9. doi: 10.1210/jc.2008-1301. PMID: 19190113.

25) Ma C, Xie J, Huang $\mathrm{X}$, Wang $\mathrm{G}$, Wang $\mathrm{Y}$, Wang $\mathrm{X}$, et al. Thyroxine alone or thyroxine plus triiodothyronine replacement therapy for hypothyroidism. Nucl Med Commun. 2009; 30(8): 586-93. PMID: 19491714.

26) Walsh JP, Shiels L, Lim EM, Bhagat CI, Ward LC, Stuckey BG, et al. Combined thyroxine/liothyronine treatment does not improve well-being, quality of life, or cognitive function compared to thyroxine alone: a randomized controlled trial in patients with primary hypothyroidism. J Clin Endocrinol Metab. 2003; 88(10):4543-50. doi: 10.1210/jc.2003-030249. PMID: 14557419.

27) Geffner DL, Azukizawa M, Hershman JM. Propylthiouracil blocks extrathyroidal conversion of thyroxine to triiodothyronine and augments thyrotropin secretion in man. J Clin Invest. 1975; 55(2): 224-9. doi: 10.1172/JCI107925. PMID: 805160, PMCID: PMC301740.

28) Bianco AC, Salvatore D, Gereben B, Berry MJ, Larsen PR. Biochemistry, cellular and molecular biology, and physiological roles of the iodothyronine selenodeiodinases. Endocr Rev. 2002; 23(1): 38-89. doi: 10.1210/edrv.23.1.0455. PMID: 11844744.

29) van der Deure WM, Appelhof BC, Peeters RP, Wiersinga WM, Wekking EM, Huyser J, et al. Polymorphisms in the brain-specific thyroid hormone transporter OATP1C1 are associated with fatigue and depression in hypothyroid patients. Clin Endocrinol. 2008; 69(5): 804-11. doi: 10.1111/j.13652265.2008.03267.x. PMID: 18410547.

30) Gullo D, Latina A, Frasca F, Le Moli R, Pellegriti G, Vigneri R. Levothyroxine monotherapy cannot guarantee euthyroidism in all athyreotic patients. PLoS One. 2011; 6(8): e22552. doi: 10.1371/journal.pone.0022552. PMID: 21829633, PMCID: PMC3148220.

31) Alevizaki M, Mantzou E, Cimponeriu AT, Alevizaki CC, Koutras DA. TSH may not be a good marker for adequate thyroid hormone replacement therapy. Wien Klin Wochenschr. 2005; 117(18): 636-40. doi: 10.1007/s00508-005-0421-0. PMID: 16416346.

32) Carta MG, Loviselli A, Hardoy MC, Massa S, Cadeddu M, Sardu C, et al. The link between thyroid autoimmunity (antithyroid peroxidase autoantibodies) with anxiety and mood disorders in the community: a field of interest for public health in the future. BMC Psychiatry. 2004; 4: 25. doi: 10.1186/1471-244X-425. PMID: 15317653, PMCID: PMC516779.

33) Padberg S, Heller K, Usadel KH, Schumm-Draeger PM. One-year prophylactic treatment of euthyroid hashimoto's thyroiditis patients with levothyroxine: Is there a benefit? Thyroid. 2001; 11(3): 249-55. doi: 10.1089/105072501750159651. PMID: 11327616.

34) Engum A, Bjoro T, Mykletun A, Dahl AA. Thyroid autoimmunity, depression and anxiety; are there any connections? An epidemiological study of a large population. J Psychosom Res. 2005; 59(5): 263-8. doi: 10.1016/j.jpsychores.2005.04.002. PMID: 16253615.

35) Balazs C, Kiss E, Leövey A, Farid NR. The immunosuppressive effect of methimazole on cell-mediated immunity is mediated by its capacity to inhibit peroxidase and to scavenge free oxygen radicals. Clin Endocrinol (Oxf). 1986; 25(1): 7-16. doi: 10.1111/j.1365-2265.1986.tb03590.x. PMID: 3024872.

36) Tomer Y. Mechanisms of Autoimmune Thyroid Diseases: From Genetics to Epigenetics. Annu Rev Pathol. 2014; 9: 147-56. doi: 10.1146/annurev-pathol-012513-104713. PMID: 24460189, PMCID: PMC4128637.

37) Umar H, Muallima N, Adam JM, Sanusi H. Hashimoto's thyroiditis following Graves' disease. Acta Med Indones. 2010; 42(1): 31-5. PMID: 20305330.

38) Așık M, Binnetoğlu E, Şen H, Tekeli Z, Uysal F, Ukinç K. Graves' disease associated with Alopecia areata developed after Hashimoto's thyroiditis. Endocrine Abstracts. 2013; 32: 309. doi: 10.1530/endoabs.32.P309. 